\title{
Modeling and control of permanent magnet synchronous generator connected to grid driven by wind turbine using fast Simulator and SVPWM Technique.
}

\author{
Samraat Sharma ${ }^{1}$,Ajay Shrivastav ${ }^{2}$, Harendra Rawat ${ }^{3}$, VilasWarudkar $^{4}$ \\ ${ }^{I}$ Samraat Sharma PG Student, Department of Electrical Engineering IFTM University, Moradabad \\ 2Dr.Ajay Srivastav Proffessor, Department of Electrical Engineering GBPANT University, Pantnagar \\ ${ }^{3}$ Dr. Harendra Rawat Assistant Professor,Department of Electrical Engineering GBPANT University, Pantnagar \\ $4 \mathrm{Dr}$ Vilas Warudkar Assistant Professor, Department of Mechanical Engineering MANIT, BHOPAL
}

\begin{abstract}
Simulation model of DDPMSG 10KW grid Connected are developed using MATLAB 2013(a) and FAST Simulator. In addition to it SVPWM technique has been applied for $10 \mathrm{KW}$ grid connected model. Space vector pulse width modulation has been used for obtaining the output voltage with less distortion. An interface has also been developed between FAST and SIMULINK with MATLAB, enabling users to implement advanced turbine controls in SIMULINK convenient block diagram. The FAST subroutines have been linked with a MATLAB standard gateway subroutine in order to Generator torque control, nacelle yaw control, and pitch control modules can be designed in the SIMULINK environment. The fully controlled converter has been used to provide separate control for active and reactive powers. The simulation results in MATLAB SIMULINK 2013a showing the model have good dynamic and static performance.
\end{abstract}

Index Terms: Direct drive permanent magnet synchronous generator, space vector pulse width modulation, fully controlled converters.

\section{Introduction}

The aim of this research is to model an autonomous control wind turbine driven permanent magnetic synchronous generator.(PMSG) which feeds alternating current (AC) power to the utility grid. Furthermore, this research also demonstrates the effects and the efficiency of PMSG wind turbine which is integrated by autonomous controllers. In order for well autonomous control, two voltage source inverters are used to control wind turbine connecting with the grid. The generator-side inverter is used to adjust the Synchronous generator as well as separating the generator from the grid when necessary. The grid-side inverter controls the power flow between the direct current (DC) bus and the AC side. Both of them are oriented control by space vector pulse width modulation (SVPWM) with back-to-back frequency inverter. Moreover, the proportional-integral (PI) controller is enhanced to control both of the of the converters and the pitch angle of the wind turbine.

\section{Inverters And The Pitch Angle Of The Wind Turbine}

According to the continuous development of wind power technology, the efficiency of inverter device is facing some tough issues and plays a vital role in the improvement of wind power generation system performance. They need to be enhanced by controller [3] to improve the efficiency and the reliability. Inside them, MPPT integrating with the back to back space vector Pulse width modulation [4] is the advantage of controller [3], which is used to measure the rotor speed and compare with the calculated optimal rotor speed. On the other hand, not only does the inverter take an advantage in efficiency control but also the pitch angle controller takes another important part of wind turbine. It is integrated to adjust the aerodynamic torque of the wind turbine when this study rates wind speed

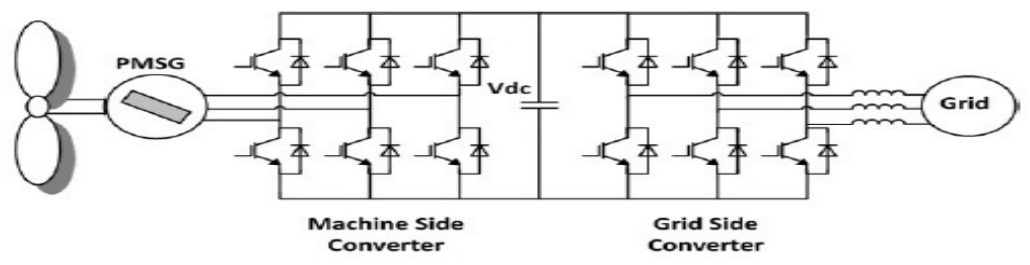

Figure1 VSC (voltage source converter) thyristor inverter. 


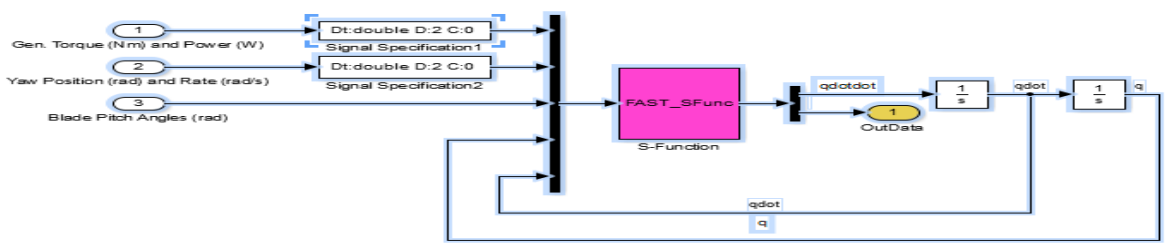

Figure 2 Fast_S Function block

FAST (Fatigue Aerodynamics Structures and Turbulence) code.

The National Renewable Energy Laboratory (NREL) FAST (Fatigue, Aerodynamics, Structures, and Turbulence) code. The FAST code is a comprehensive aero elastic simulator capable of predicting both the extreme and fatigue loads of two and three bladed horizontal-axis wind turbines [8]. This simulator has been chosen for validation because in 2005, it was evaluated by German ischer Lloyd Wind Energy and found to be suitable for the calculation of onshore wind turbine loads for design and certification. During time-marching analysis, FAST makes it possible to control the turbine and model specific conditions in many ways. Five basic methods of control are available: pitching the blades, controlling the generator torque, applying the high-speed shaft. brake, deploying the tip brakes, and yawing the nacelle. The simpler methods of controlling the turbine require nothing more than setting some of the appropriate input parameters in the turbine control section of the primary input file. Methods of control that are more complicated (that is our case) require writing specific routines, compiling them, and linking them with the rest of the program [8]. An interface has also been developed between FAST and SIMULINK with MATLAB, enabling users to implement advanced turbine controls in SIMULINK convenient block diagram form. The FAST subroutines have been linked with a MATLAB standard gateway subroutine in order to use the FAST equations of motion in an S-function that can be incorporated in a SIMULINK model. This introduces tremendous flexibility in wind turbine control implementation during simulation. Generator torque control, nacelle yaw control, and pitch control modules can be designed in the SIMULINK environment and simulated while making use of the complete nonlinear aeroelastic wind turbine equations of motion available in FAST. The wind turbine block, as shown in Fig2, contains the S-function block with the FAST motion equations. It also contains blocks that integrate the degree-of-freedom accelerations to get velocities and displacements. Thus, the equations of motion are formulated in the FAST S-function but solved using one of the SIMULINK solvers.

\section{Model Of PMSG}

Structure of PMSG Wind Turbine. The basic of PMSG wind turbine structure shown on Figure 1 is defined as [10]. The wind turbine generates torque from wind power. The torque is transferred through the generator shaft to the rotor of the generator. The generator produces an electrical torque, and the difference between the mechanical torque from the wind turbine and the electrical torque from the generator determines whether the mechanical system accelerates, decelerates, or remains at constant speed. The generator is connected to a three-phase inverter which rectifies the current from the generator to charge a DC-link Vdc capacitor [11]. The DC-link Vdc feeds a second three-phase inverter which is connected to the grid through a transformer. Through the control system, the information of wind speed, pitch angel, rotor RPM, and inverter output is accepted to compare with the grid-side data. Therefore, this information is solved by using a digital signal processing. The LCL filter is connected between inverter and Grid to remove the harmonic content in the voltage output. The dc link capacitor is placed between the rectifier and the inverter. The purpose of dc link capacitor is remove the ripples in the dc link voltage and size of the capacitor have to trade of between ripples and response time.D-q axis voltages equations after parks transform. 


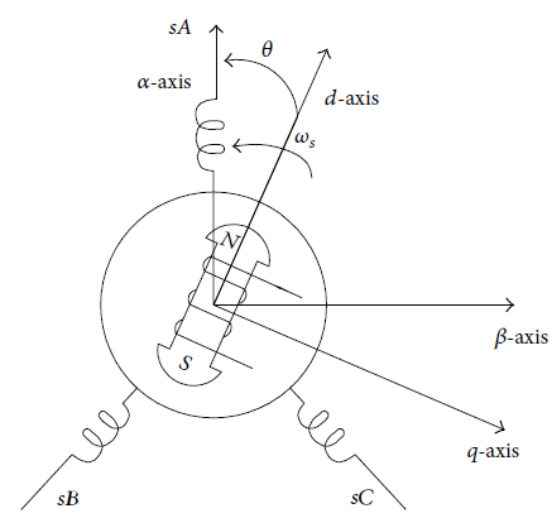

Figure 3 DQ axis frame of PMSG

$\omega_{\mathrm{e}}$ the frequency of the generator's emf and $\mathrm{p}$ is the number of generator pole pairs.voltage equatoin of the PMSG in dq reference frame.

$$
\begin{aligned}
& V_{d}=R i_{d}-\omega_{\theta} L_{q} i_{q}+L_{d} \frac{d i_{d}}{d t} \\
& V_{q}=R i_{q}-\omega_{\theta}\left(L_{d} i_{d}+\psi\right)+L_{q} \frac{d i_{q}}{d t}
\end{aligned}
$$

The electrical and mechanical angle relation given below. shows the $d q$-coordinates frame of the PMSG with $\theta$ being the angle between $d$-axis and the main stator axis. $\mathrm{V}_{\mathrm{d}}, \mathrm{V}_{\mathrm{q}}$ and id, iq are voltages and current of direct and quadrature axis.Ld and Lq are generator inductance

$$
\theta_{\text {electrical }}=\mathrm{p} \theta \mathrm{r}
$$

$$
\omega_{\mathrm{e}}=\mathrm{p} \omega_{\mathrm{r}}
$$

$\omega$ e is the basic electrical angular frequency of the generator.The direct and quadrature axis Voltage by parks transform

$$
V_{d}=R i_{d}-p \omega_{r} L_{q} i_{q}+L_{d} \frac{d i_{d}}{d t}
$$

The electrical torque is given by

$$
\tau_{e}=\frac{3}{2} \mathrm{p}\left(\mathrm{i}_{\mathrm{d}} \mathrm{i}_{\mathrm{q}}\left(\mathrm{L}_{\mathrm{d}}-\mathrm{L}_{\mathrm{q}}\right)+\psi i_{\mathrm{q}}\right.
$$

The machine is non salient therefore $\mathrm{L}_{\mathrm{d}}=\mathrm{L}_{\mathrm{q}}=\mathrm{L}_{\mathrm{s}}$ applying in above equation we get.

$$
\begin{aligned}
& V_{q}=R i_{q}-p \omega_{r}\left(L_{d} i_{d}+\psi\right)+L_{q} \frac{d i_{q}}{d t} \\
& V_{d}=R i_{d}-L_{s}\left(\frac{d i_{d}}{d t}-p \omega_{r} i_{q}\right) \\
& \tau_{\theta}=\frac{3}{2} \mathrm{p} \psi \mathrm{i}_{\mathrm{q}}
\end{aligned}
$$

This are equation of non salient rotor of PMSG. 


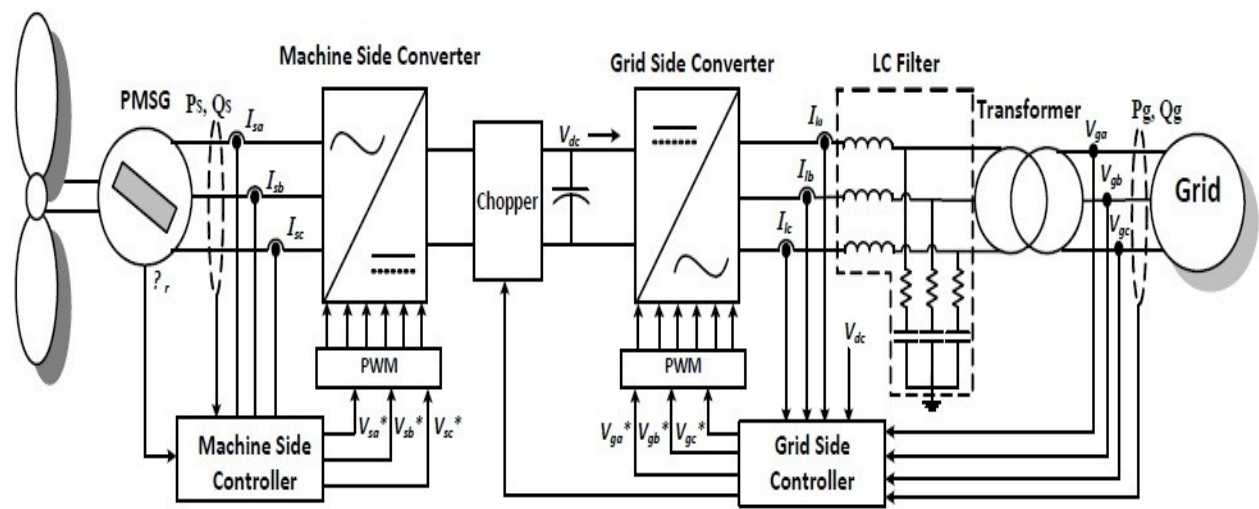

Figure 4 PMSG Complete Control System

It is made of three power electronics equipments

(a) Rectifier (AC/DC converter),

(b) Chopper (DC/DC converter)

(c) Inverter (DC / AC converter)

\section{Space-Vector Pulse-Width Modulation}

Another method of obtaining a pulse width modulation is based on space vector representation of the switching voltages in the $\alpha \beta$ plane as described by (Vander Broeck et al, 1988; Lindberg, 1990). This method has the advantage of being easier to implement than other PWM techniques and achieves similar results to regular sampled sinusoidal PWM with third harmonic added to the reference waveform. Therefore, the harmonic content of the output waveform is lower than that for an equivalent CB-PWM. A single rotating vector can be used to represent three-phase voltages. This vector is called the voltage space vector which generally rotates in a two-dimension plane. In this case, two stationary perpendicular axis, $\alpha$ and $\beta$, are used to represent the voltage space vector. For a two-level converter using the space vector PWM switching strategy, the switching vectors are defined by the states of the converter switches as shown in Figure. Three switching legs, each having two states $\mathrm{ON}$ or OFF, allow the converter to produce $\left(2^{3}=8\right)$ eight possible switching states Figure 3.5(c) .In the SV-PWM technique, the sequence of the switching vectors is selected in such a way that only one leg is switched to move from one switching vector to the next. This switching sequence is achieved by arranging the adjacent active vectors and two-null vectors (Boost and Ziogas, 1988; Holtz, 1992). The switching times of the switching vectors are calculated by equating volt-second integrals between the required voltage vector and the switching vectors. Figure5 shows an example for the calculation of switching times, when the required voltage vector is in the first sector.

\begin{tabular}{|l|l|l|r|r|r|c|}
\hline $\mathrm{S}_{a}$ & $\mathrm{~S}_{b}$ & $\mathrm{~S}_{c}$ & $v_{a o}$ & $v_{b o}$ & $v_{c o}$ & $\begin{array}{l}\text { Switching } \\
\text { vector }\end{array}$ \\
\hline 0 & 0 & 0 & $-V_{\mathrm{DC}}$ & $-V_{\mathrm{DC}}$ & $-V_{\mathrm{DC}}$ & $V_{0}$ \\
\hline 1 & 0 & 0 & $+V_{\mathrm{DC}}$ & $-V_{\mathrm{DC}}$ & $-V_{\mathrm{DC}}$ & $V_{1}$ \\
\hline 1 & 1 & 0 & $+V_{\mathrm{DC}}$ & $+V_{\mathrm{DC}}$ & $-V_{\mathrm{DC}}$ & $V_{2}$ \\
\hline 0 & 1 & 0 & $-V_{\mathrm{DC}}$ & $+V_{\mathrm{DC}}$ & $-V_{\mathrm{DC}}$ & $V_{3}$ \\
\hline 0 & 1 & 1 & $-V_{\mathrm{DC}}$ & $+V_{\mathrm{DC}}$ & $+V_{\mathrm{DC}}$ & $V_{4}$ \\
\hline 0 & 0 & 1 & $-V_{\mathrm{DC}}$ & $-V_{\mathrm{DC}}$ & $+V_{\mathrm{DC}}$ & $V_{5}$ \\
\hline 1 & 0 & 1 & $+V_{\mathrm{DC}}$ & $-V_{\mathrm{DC}}$ & $+V_{\mathrm{DC}}$ & $V_{6}$ \\
\hline 1 & 1 & 1 & $+V_{\mathrm{DC}}$ & $+V_{\mathrm{DC}}$ & $+V_{\mathrm{DC}}$ & $V_{7}$ \\
\hline
\end{tabular}

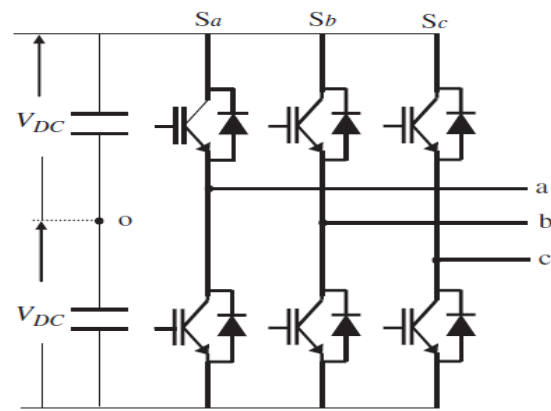

Figure5 Switching status of a six-pulse converter switches 


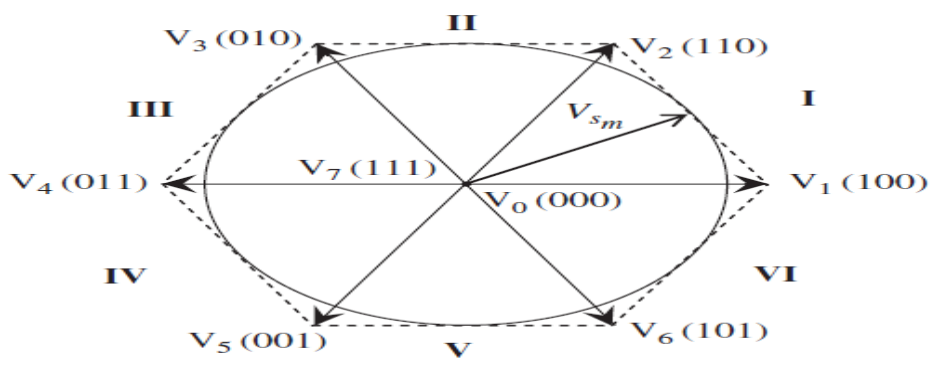

Figure 6 Switching vector positions for 2-level SVPWM

The space-vectors are plotted in MATLAB by the $\alpha \beta$ (Clarke transform block just like parks transform block)

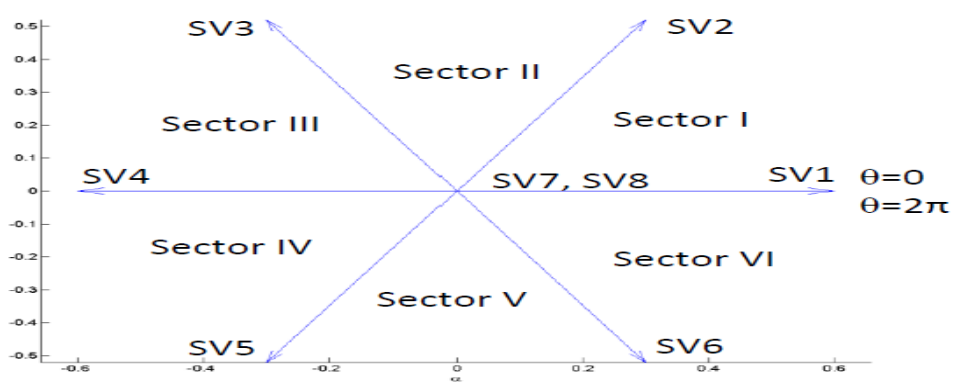

Figure7 Space vector using Clarke $(\alpha, \beta)$ and park block $(d, q)$ in Matlab.

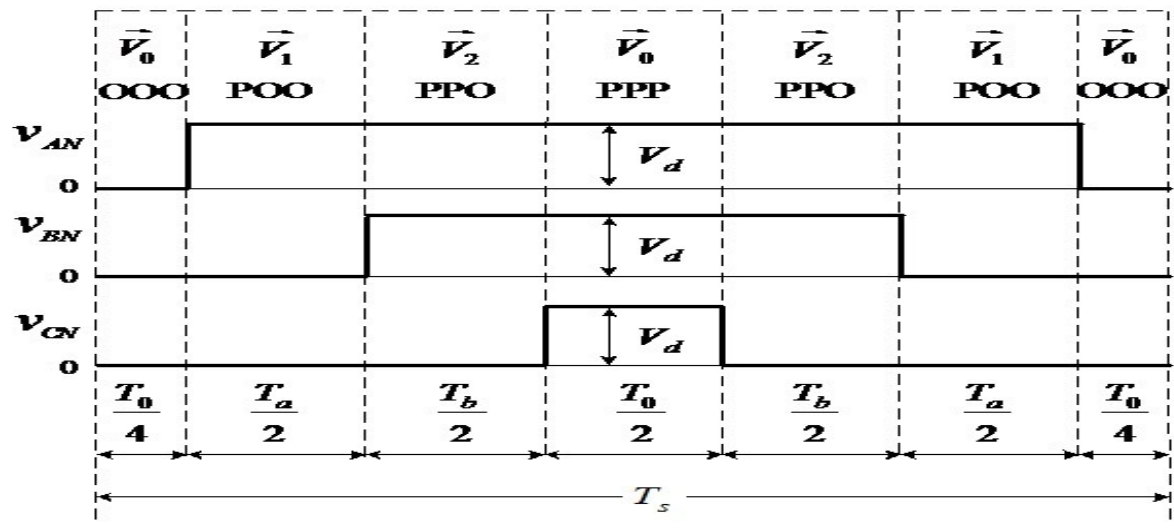

Figure8 Seven-segment Switching Sequence

Selected vectors: $V_{0}, V_{1}$ and $V_{2}$ Dwell times: $T_{s}=T_{0}+T_{a}+T_{b}$

\section{Controllers}

Generator-Side Inverter Controller.

The generator-side inverter is controlled to catch maximum power from available wind power. According to (5), in order to control the electromagnetic torque $T e$, this study just controls the $q$-axis current is with the assumption that the $d$-axis current $i d$ is equal to zero. Furthermore, $[3,14]$ show that, in order to catch maximum power, the optimum value of the rotation speed is adjusted. The tip speed ratio $\lambda$ is taken into account due to

$\lambda_{\text {opt }}=\left(\omega_{\text {ref }} \mathrm{R}\right) / \mathrm{v}$

with $E s=\mathrm{p} \omega_{\mathrm{r}} \cdot \psi$ being the permanent flux linkages.

The generator-side inverter control schematic is illustrated in Figure 6. Through the MPPT in [5], the error of $\omega_{\text {ref }}$ is produced. Therefore, the error of $\omega_{\text {ref }}$ and $\omega_{s}$ is rescued to PI controller to produce $q$-axis current component $i q$ ref which put into space vector pulse width modulation (SVPWM).The $d$-axis current $i d$ ref is set to zero because the $d$-axis current control is adopted. Consequently, through the SVPWM containing voltage feed-forward compensation, the power factors of the generator are calculated and controlled well.

$V_{d}=R i_{d}-L_{s}\left(\frac{d i_{d}}{d t}-p \omega_{r} i_{q}\right)$

$V_{\mathrm{q}}=R \mathrm{R}_{\mathrm{q}}-\mathrm{L}_{\mathrm{s}}\left(\frac{d \mathrm{i}_{\mathrm{d}}}{\mathrm{dt}}+\mathrm{p} \omega_{\mathrm{r}} \mathrm{i}_{\mathrm{d}}\right)+\mathrm{p} \omega_{\mathrm{r}} \psi$ 
There, ${ }_{\text {ref }}$ is the blades angular velocity reference and $\lambda_{\text {opt }}$ is the tip speed ratio optimum.

Grid-Side Inverter Controller

The goal of the grid-side inverter is keeping the stability of the DC-line voltage as well as controlling the active and reactive power Here, $\mathrm{V} d$ is the $d$-axis output voltage of the grid, respectively, $\omega$ is the angular frequency in electrical degree of grid, $R$ is the resistance, $L$ is the inductance, respectively, and $i d$ and $i q$ are the currents of $d$-axis and $q$-axis. It is easy to figure out that the current of $d$-axis and $q$-axis can be controlled to moderate the active and reactive power. The inner current loop is controlled through PI controller similar to generator side inverter controller. The output voltage loop produces PI controller for calculating the error between $\mathrm{V} d c$ and $\mathrm{V} d c$ ref to produce $i d$ ref. Therefore, $q$-axis current is set to be zero to decoupling control of the active power $P$ and reactive power $Q$ by moderating the $d$-axis current $i d$ and the $q$-axis current $i q$.

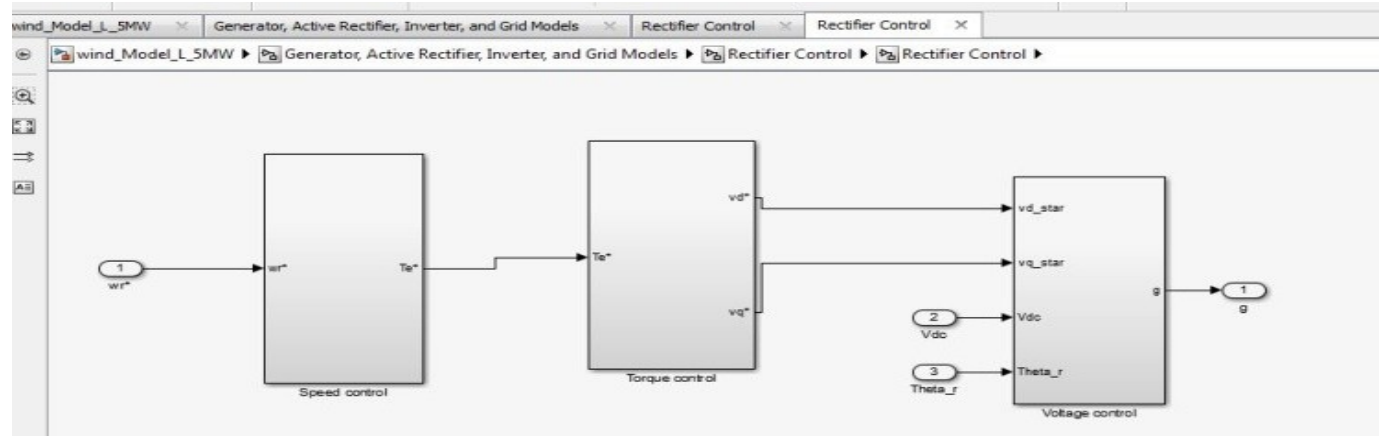

Figure9 Rectifier model control SIMULINK model under scope on inverter control

Pitch Angle Controller.

Pitch angle controller is based on the principle which is changing the blades angle at the revolutions over the maximum generator speed as well as protecting the generator before overloading at high wind speeds. The optimal angle for the wind speed below the nominal value is approximately zero and then it increases with the wind speed. The speed of the generator is compared with its reference value through PI controller to have the output value of the pitch angle of the blades, which changes the performance coefficient of the turbine.

\section{Maximum Power Point Tracking}

In the generator-side inverter, MPPT produces the $\omega$ ref for the comparative PI controller. the wind turbine coefficient achieves the maximum for the tip speed, when the pitch angle $\beta=0$. In terms of every wind speed, there exists a specific point to get the maximum output. Hence, in order to control the maximum power in every wind speed, the MPPT tracks the continuous line and optimal line. The tip speed ratio is kept at constant value for all maximum power points, while the relationship between the wind speed and the wind turbine generator speed is explained as follows:

$\Omega=\lambda \frac{\mathrm{V}}{\mathrm{R}}$

$\Omega$ is the optimal rotation wind turbine generator At wind speed V. The MPPT control strategy is based on monitoring the wind turbine generator output power using measurements of the wind turbine generator output voltage and current as well as directly modeling the dc/dc converter duty cycle, which is followed by the comparison of among output power values.

Table 2: Transformer Properties

\begin{tabular}{|r|l|l|}
\hline S. No. & Symbol & $\mathbf{1 0 ~ K w}$ \\
\hline $\mathbf{1 .}$ & V (primary) & $90.13 \mathrm{~V}$ \\
\hline $\mathbf{2 .}$ & V (secondary) & $208 \mathrm{~V}$ \\
\hline $\mathbf{3 .}$ & Nominal power & $20 \mathrm{kVA}$ \\
\hline $\mathbf{4 .}$ & Series resistance (primary) & $0.0043264 \Omega$ \\
\hline $\mathbf{5 .}$ & Series resistance (secondary) & $8.124 * 10-4 \Omega$ \\
\hline $\mathbf{6 .}$ & Series inductance (primary) & $0.574 \mathrm{mH}$ \\
\hline $\mathbf{7 .}$ & Series inductance (secondary) & $86.198 \mu \mathrm{H}$ \\
\hline $\mathbf{8 .}$ & Magnetizing resistance & $1086.6 \Omega$ \\
\hline $\mathbf{9 .}$ & Switching frequency & $2.869 \mathrm{H}$ \\
\hline
\end{tabular}


Table 3: Electrical Model Parameters Parameter

\begin{tabular}{|r|l|l|}
\hline S. No. & Symbol & $\mathbf{1 0 ~ K w}$ \\
\hline $\mathbf{1 .}$ & Nominal grid voltage & $208 \mathrm{~V} \mathrm{3}$ \\
\hline $\mathbf{2 .}$ & Nominal grid frequency & $60 \mathrm{~Hz}$ \\
\hline $\mathbf{3 .}$ & Nominal PMSG voltage & $260 \mathrm{~V}$ \\
\hline $\mathbf{4 .}$ & $\mathrm{C}_{\mathrm{DC}}$ & $600 \mu \mathrm{F}$ \\
\hline $\mathbf{5 .}$ & $\begin{array}{l}\text { IGBT forward voltage } \\
\text { drop }\end{array}$ & $2.0 \mathrm{~V}$ \\
\hline $\mathbf{6 .}$ & $\begin{array}{l}\text { Diode forward voltage } \\
\text { drop }\end{array}$ & $1.0 \mathrm{~V}$ \\
\hline $\mathbf{7 .}$ & $\begin{array}{l}\text { IGBT conducting } \\
\text { resistance }\end{array}$ & $55 \mathrm{~m} \Omega$ \\
\hline $\mathbf{8 .}$ & IGBT fall time & $70 \mathrm{~ns}$ \\
\hline $\mathbf{9 .}$ & Switching frequency & $7 \mathrm{kHz}$ \\
\hline $\mathbf{1 0 .}$ & Transformer turns ratio & $1: 2.30771$ \\
\hline & &
\end{tabular}

\section{TABLE 4 Aeroelastic Model Summary}

\begin{tabular}{|c|c|c|}
\hline SNO & Parameter & $\mathbf{1 0 ~ k W ~ T u r b i n e}$ \\
\hline 1 & Rotor diameter & $7 \mathrm{~m}$ \\
\hline 2 & Nacelle mass & $260.5 \mathrm{~kg}$ \\
\hline 3 & Nacelle inertia & $39.81 \mathrm{~kg} \mathrm{~m}^{2}$ \\
\hline 4 & Generator inertia & $0.5 \mathrm{~kg} \mathrm{~m}^{2}$ \\
\hline 5 & Hub inertia & $7.71 \mathrm{~kg} \mathrm{~m}^{2}$ \\
\hline 6 & Blade nodes for BEM & 15 \\
\hline 7 & Blade mass & $21.7724 \mathrm{~kg}$ \\
\hline
\end{tabular}

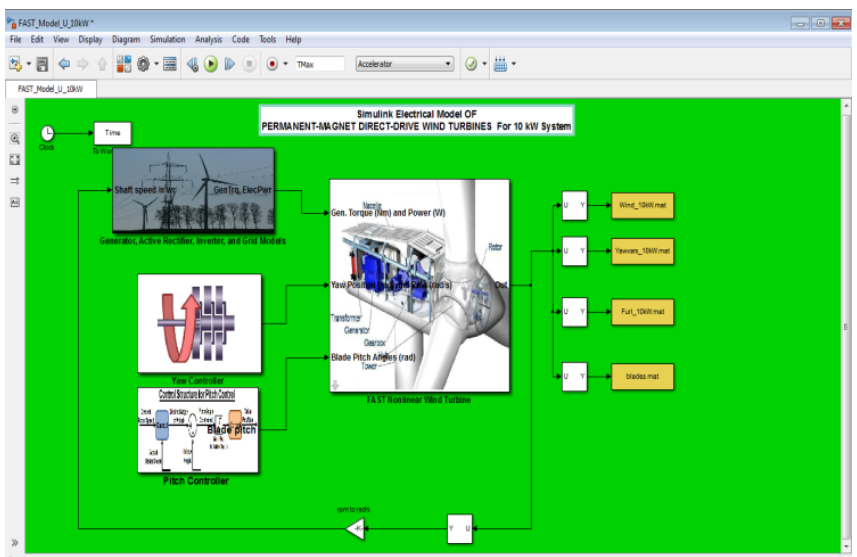

Figure7 Simulation Model of 5MW KW of PMDD Wind Turbine.

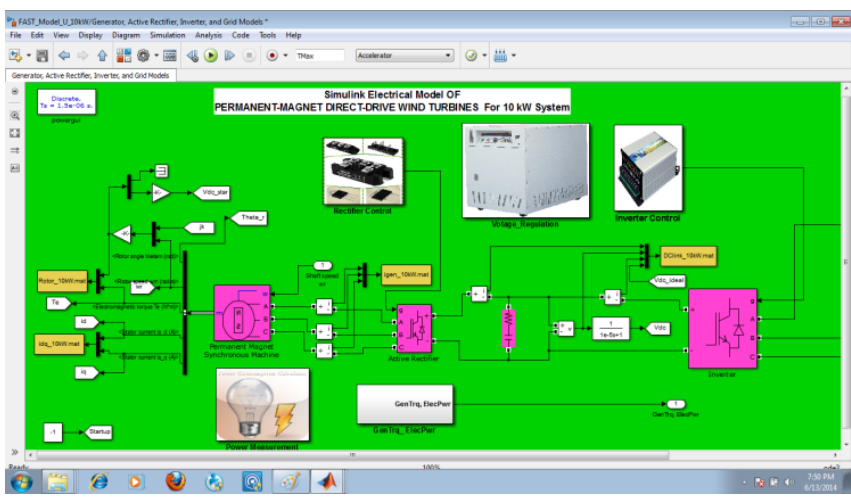

Figure8 Electrical Model For 5MW PMSG Grid Connected

The electrical model consist of PMSG block of 5 MW. Universal bride(Consist of IGBT both generator and inverter side),Rectifier control block ,Inverter control block Power grid block, Voltage regulation block, LCL filter and dc link ,Power calculation and Power GUI block. 


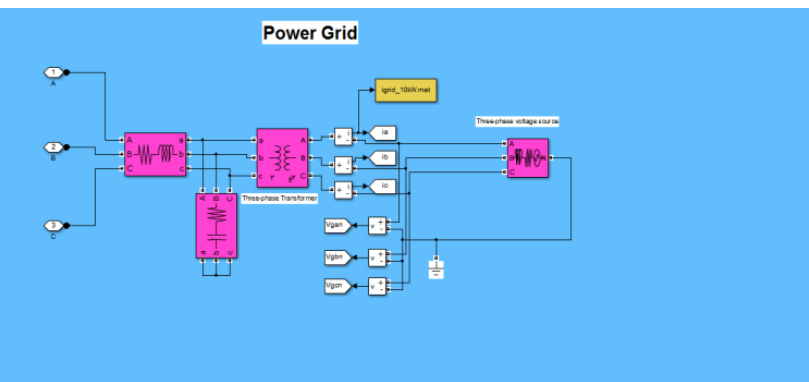

Figure9 Power Grid Block.

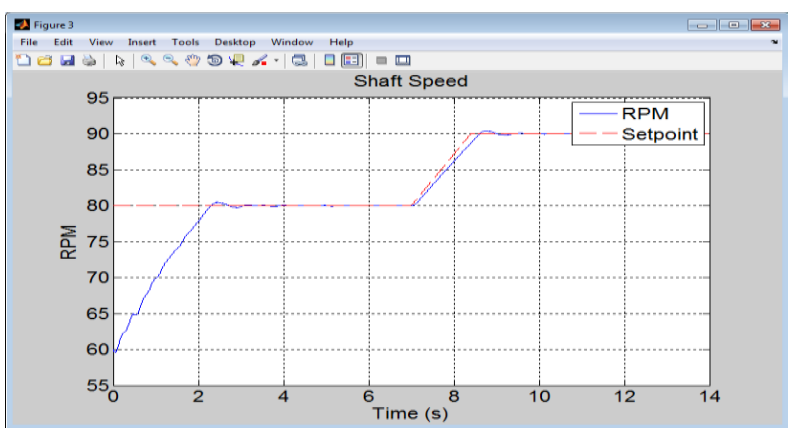

Figure 10 Shaft Speed(5MW)

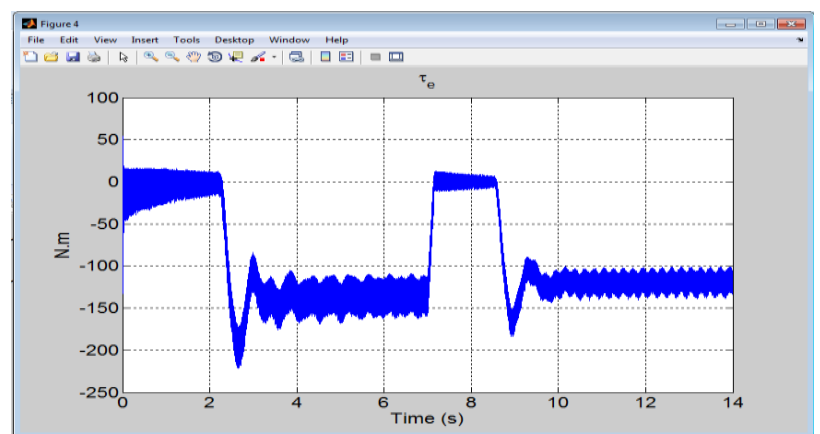

Figure 11 Electrical Torque(10KW)

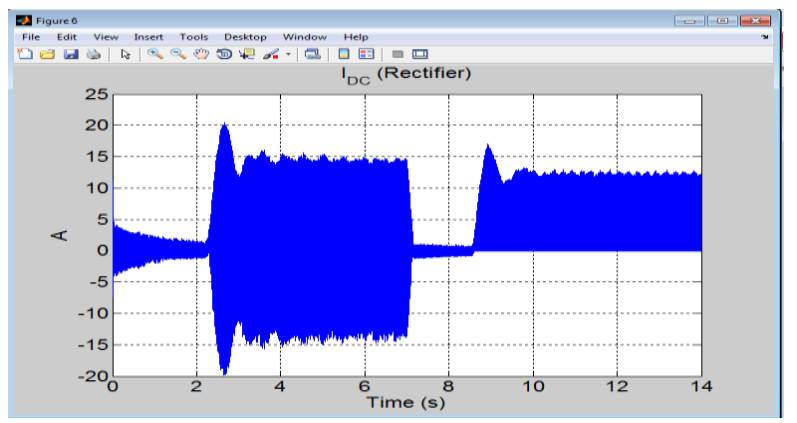

Figure12 Idc(Rectifier) (10KW)

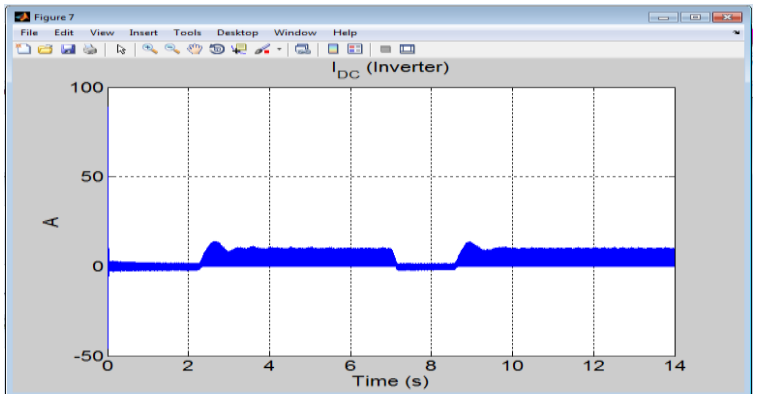

Figure13 Idc(inverter) (10KW) 


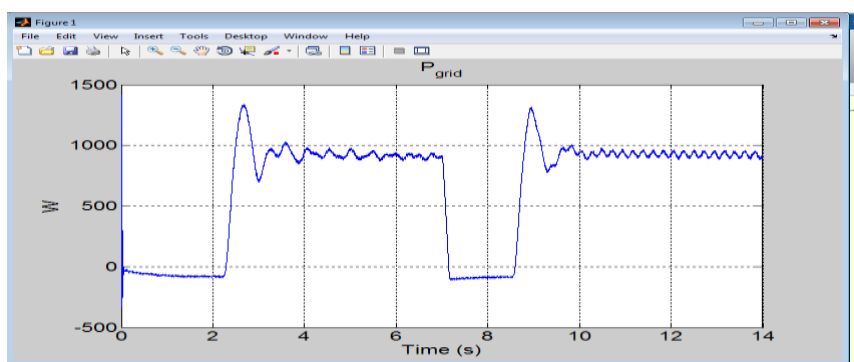

Figure14 ACTIVE_POWER (grid) (10KW)

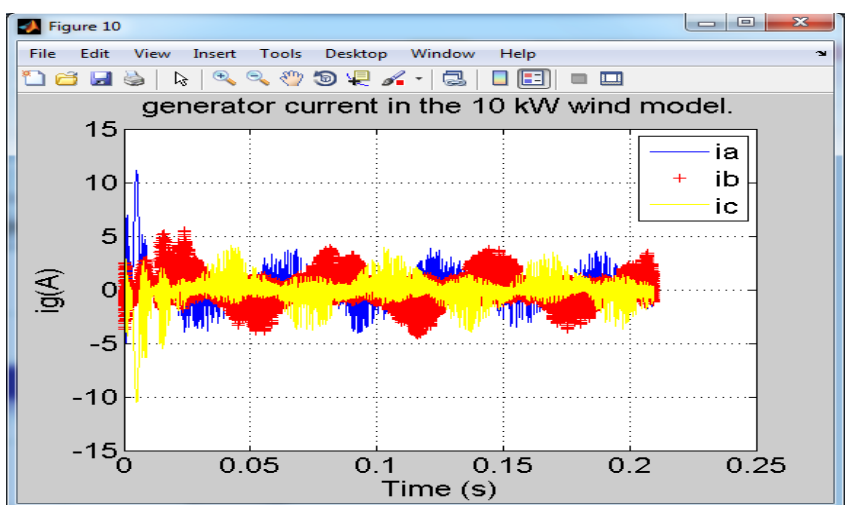

Figure15 $\mathrm{I}_{\mathrm{a}}, \mathrm{I}_{\mathrm{b}}, \mathrm{I}_{\mathrm{c}}$ Stator current from PMSG(10KW)

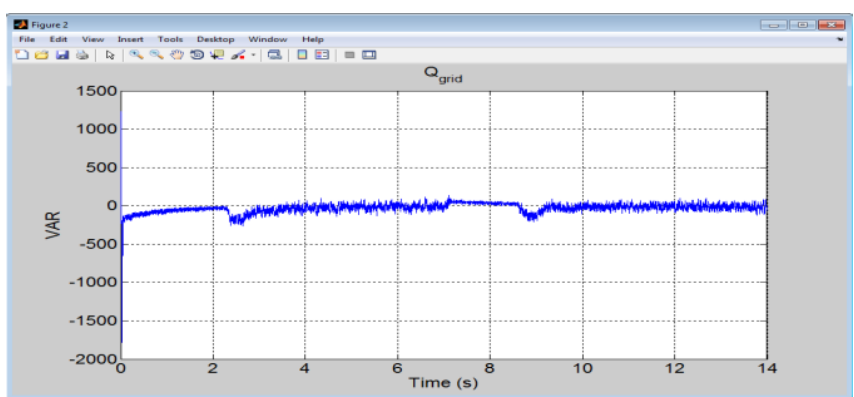

Figure 16 REACTIVE_POWER (grid) (10KW)

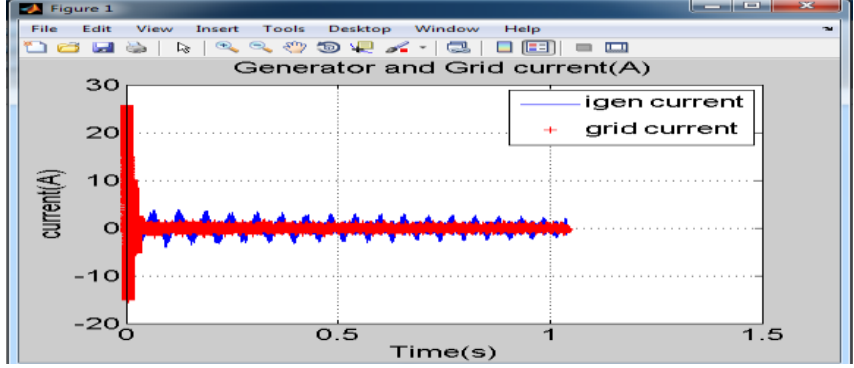

Figure17 Generator and grid current $(10 \mathrm{KW})$

In figure 10 the shaft speed varies from 60 to $90 \mathrm{rpm}$. In figure 11 the electrical torque is negative. Figure 12 and 13 show $I_{\mathrm{dc}}$ of rectifier and inverter. Figure 14 and 16 shows active and reactive power. Figure 15 shows stator current of PMSG. Figure 17 shows generator and grid current.

The figure 14 shows that the reactive power performs the waves of active power and reactive power decoupling control When the wind turbine catches the wind speed at rate $5 \mathrm{~m} / \mathrm{s}$, PMSG begins to operate.

Figure 13 shows the waves of DC-link current, the voltage is produced by grid-side inverter and A-phase voltage feeding to the grid. Through the results, it is admitted that DC voltage is well controlled in stabilizing performance with the Fluctuation being about $25 \%$.Therefore. Pitch angle controller catches the optimum tip speed ratio at 8 and optimum power coefficient at 0.4 through the maximum power point tracking. On the other hand, grid-side inverter models the output voltage with the DC-link voltage in accordance with DC link capacitor 
.After all, PMSG wind turbine with autonomous control system produces the grid line voltage .In figure 17 generator and grid current are shown. The negative Torque is show in the figure 11 showing the generating mode.

\section{Conclusions}

This study analyzes the control strategies as well as models and designs of 5MW DDPMSG wind turbine and simulates the whole autonomous system of PMSG wind turbine feeding AC power to the utility grid in Matlab Simulink 2013a. The simulation results show that the combination of pitch angle controller, generator-side inverter controller, and grid-side inverter controller has good dynamic and static performance. The maximum power can be obtained using SVPWM modulation technique and the generator wind turbine can be operated in high efficiency. DC-link voltage is kept at stable level for decoupling control of active and reactive power. The DC voltage utilization ratio which may be around $71 \%$ of the DC link voltage as compared to the conventional sine-pulse width Modulation which is $61.2 \%$ in the linear modulation range. Space vector PWM generates less harmonic distortion in the output voltage or current waveform in comparison to a Sine PWM and it also decreases the harmonic content in the output waveform. Hence, the output will get the optimum power supply for the grid.

[1] N. Freire and J. Estima, "A Comparative Analysis of PMSG Drives Based on Vector Control and Direct Control Techniques for Wind Turbine Applications,” PRZEGLĄD ELEKTROTECHNICZNY (Electrical Review), ISSN 0033-2097 no. 1, pp. 184-187, 2014

[2] Tan and S. Islam, "Optimum control strategies in energy conversion of PMSG wind turbine system without mechanical sensors," IEEE Transction on Energy Conversion, vol. 19, pp. 392-9, June 2004[3]

[3] Eftichios Koutroulis ,Kostas Kalaitzakis "Design of a Maximum Power Tracking System for Wind-Energy-Conversion Applications Proceedings of the IEEE transactions on industrial electronics", vol. 53, no. 2, april 2006[4].

[4] M. Chinchilla, "Control of permanent-magnet generators applied to variable-speed wind-energy systems connected to the grid," Energy Conversion, IEEE transitions vol. 21, no. March, pp. 130-135, 2006.

[5] Jamal A. Baroudi, Venkata Dinavahi_, Andrew M. Knight, “ A review of power converter topologies for wind generators.” J.A. Baroudi et al. Renewable Energy Science direct Elsevier (2007) 2369-2385.

[6] R. Fadaeinedjad, "Simulation of a wind turbine with doubly fed induction generator by FAST and Simulink," IEEE Transtions on Energy conversion, vol. 23, no. 2, pp. 690-700, 2008.

[7] B. Beltran,"High-order sliding-mode control of variable-speed wind turbines, IEEE Transaction on Industrial Electronics, vol. 56, no. 9, pp. 3314-3321, 2009.

[8] S. Belakehal, H. Benalla, A. Bentounsi, "Power maximization control of small wind system using permanent magnet synchronous generator," Revnouvelables energies vol. 12, pp. 307-319, 2009.

[9] Alejandro Rolan', Alvaro Luna, Gerardo Vazquez, Daniel Aguila "Modeling of a Variable Speed Wind Turbine with a Permanent Magnet Synchronous Generator IEEE International Symposium on Industrial Electronics” (ISIE 2009)Seoul Olympic Parktel, Seoul, Korea July 5-8, 2009.

[10] Z. Inverter, S. M. Dehghan, S. Member, M. Mohamadian, "A New Variable-Speed Wind Energy Conversion System Using Permanent-Magnet Synchronous,” the IEEE transactions on Energy conversion . vol. 24, no. 3, pp. 714-724, 2009.

[11] R. Melício ,V.M.F. Mendes , J.P.S. Catalão "Power converter topologies for wind energy conversion systems: Integrated modeling, control strategy and performance simulation.” Journal Elsevier R. Melício et al. / Renewable Energy Science direct Elesvier (2010) 2165e2174. 10 April 2010.

[12] M. Van Dessel, M. Gay, G. Deconinck, "Simulation of grid connected PM generator for wind turbines," 2010 IEEE Int. Symp. Industrial Electronics, pp. 1479-1484, Jul. 2010.

[13] Yinan Cui, Hasan Shanechi, Mohammad Shahidehpour, "Investigation into Use of PMSG-based Wind Farm for Grid Support". IEEE transactions on regular papers 2011.

[14] Mirza Mohd. Shadab, Abu Tariq, M.A.Mallick, "Simulation And Control Of 20 Kw Grid Connected Wind System. Proceedings of the International Journal of Electrical And Electronics Engineering Research" (IJEEER) ISSN 2250-155X Vol. 3, Issue 3, Aug 2012, 275-284

[15] P. Bouchard, "A method of tracking maximum power points in variable speed wind energy conversion systems," 2012 in International Symposium on Power Electronics, Electrical Drives, Automation and MotionPower Electron.2012.

[16] Faeka Khater and Alaa Omar. "A Review of Direct Driven PMSG for Wind Energy Systems. Journal of Energy and Power Engineering" 7 (2013) 1592-1603. Journal of Energy and Power Engineering david publishing. (2013) 1592-1603.

[17] Hamid Shariatpanah, Roohollah Fadaeinedjad, Masood Rashidinejad, "A new model for PMSG-based wind turbine with yaw control IEEE transactions on energy conversion", vol. 28, no. 4, december 2013.

[18] Mirza Mohd.Shadab, Abu Tariq 2012,"Performance analysis of permanent magnet synchronous generator connected with wind turbine". Proceedings of the International Journal of Advanced Technology \& Engineering Research (IJATER) ISSN NO: 2250-3536 VOLUME 2, ISSUE 2, MAY 2013.

[19] E. Mahersi, A. Khedher, M. F. Mimouni, "The Wind energy Conversion System Using PMSG Controlled by Vector Control and SMC Strategies,"published in international journal of renewable energy research Vol.3, No.1, 2013 vol. 3, no. 1, 2013.[24]

[20] Natalia Angela Orlando, Marco Liserre, , Rosa Anna Mastromauro, M and Antonio Dell'Aquila. "A Survey of Control Issues in PMSG-Based Small Wind-Turbine Systems. Proceedings of IEEE transactions on industrial

[21] D. Ahmed and a Ahmad, "An optimal design of coreless direct-drive axial flux permanent magnet generator for wind turbine," J. Phys. Conf. Ser., vol. 439, p. 012039, Jun. 2013.

[22] B. Plangklang, S. Kantawong, and A. Noppakant, "Study of Generator Mode on Permanent Magnet Synchronous Motor (PMSM) for Application on Elevator Energy Regenerative Unit (EERU)," Energy Procedia, vol. 34, pp. 382-389, Jan. 2013.

[23] Y. Xia, K. Ahmed, and B. Williams, "Wind turbine power coefficient analysis of a new maximum power point tracking technique," IEEE transition on industrial Electronics. vol. 60, no. 3, pp. 1122-1132, 2013.

[24] G. Revel, A. Leon, D. Alonso, and J. Moiola, "Dynamics and Stability Analysis of a Power System With a PMSG-Based Wind Farm Performing Ancillary Services," IEEE transiction on , pp. 1-12, 2014. 
[25] S. Alshibani at el,“Lifetime Cost Assessment of Permanent Magnet Synchronous Generators for MW Level Wind Turbines,",IEEE transition on industrial electronic. vol. 5, no. 1, pp. 10-17, 2014

[26] D. Ochs, R. Miller, and W. White, "Simulation of Electromechanical Interactions of Permanent-Magnet Direct-Drive Wind Turbines Using the FAST Aeroelastic Simulator," pp. 1-8, 2014.

[27] ION BOLDEA "Variable Speed Generators "The electrical Generator handbook Published in 2006 by CRC Press Taylor \& Francis Group.

[28] OLIMPO ANAYA-LARA, NICK JENKINS “Wind Energy Modulation and Control” John Wiley \& Sons, Ltd 2009

[29] MUKUND R PATEL "Wind and Solar Power System" CRC Press 2011Edition.

[30] JOSHUA EARNEST \& TORE WILZELIUS “Wind Power Plant and Projects Development" PHI learning 2012Edition 